\title{
Social media adoption and resulting tactics in the U.S. federal government
}

\author{
Ines Mergel * \\ Department of Public Administration and International Affairs, Maxwell School of Citizenship and Public Affairs, Syracuse University, 436 Crouse-Hinds Hall, Syracuse, NY 13233, USA
}

Keywords:

Social media adoption

Technology adoption

Diffusion of innovation

Qualitative network analysis

\begin{abstract}
A B S T R A C T
In 2009, the departments in the executive branch of the U.S. federal government received the presidential marching order to "harness new technologies" in order to become more transparent, collaborative and par ticipatory. Given this mandate, this article sets out to provide insights from qualitative interviews with social media directors to understand the factors that influence internal adoption decisions to use social media ap plications, such as Facebook, Twitter, or blogs. Three distinct factors influence the adoption decisions of social media directors: information about best practices in their informal network of peers, passive observations of perceived best practices in the public and private sector, and "market driven" citizen behavior. The resulting adoption tactics include: (1) representation, (2) engagement, and (3) networking. The findings point to the need for higher degrees of formalized knowledge sharing when it comes to disruptive technology innova tions such as social media use in highly bureaucratic communication environments. Recommendations based on the lessons learned are provided for practitioners and social media researchers to develop social media tactics for different organizational purposes in government.
\end{abstract}

\section{Introduction: Social media in the public sector}

Social media applications have become acceptable information and communication channels in the U.S. federal government during the last three or four years. After an initial informal experimentation period, a presidential directive the "Open Government Initiative" fo cused the speed and direction of the use of social media applications among the executive departments of the U.S. federal government (Obama, 2009).

Social media applications are operated outside the information and communication infrastructure of government on third party platforms. Common features of social media applications include profile pages that display descriptive information about the user, contact or friend lists, co creation and sharing of content, such as text, photos or videos, pos sibilities for public and private messaging or commenting functions (for a complete overview see for example Boyd \& Ellison, 2007). Appli cations, such as Facebook, attract more than 100 million unique visitors a month and provide the ability for "social searches" trusted informa tion sourcing in a social network's newsfeed that enables users to pay attention to information posted by their contacts (Watts, Dodds, \& Newmark, 2002).

While every administration in the past forty years has developed a variation of Open Government, the Obama Administration has clearly defined information as a public asset that needs to be shared with cit izens. The memo instructs executive departments and agencies to

\footnotetext{
* Fax: +1 3154431075.

E-mail address: iamergel@maxwell.syr.edu.
}

"harness new technologies to put information about their operations and decisions online and readily available to the public" (Obama, 2009).

As a result, most departments, agencies and initiatives now provide connections to social media applications in form of buttons placed prom inently on their main websites. Social media practices in the public sector include the use of online social networking services, such as Facebook, YouTube, Twitter, blogs or other digital media sharing sites to support the organization's mission, service delivery, as well as issue and rela tionship management with the public (Bretschneider \& Mergel, 2010; Mergel, 2010, 2011). As of April 2012, a total of 699 organizational units (including initiatives, teams, and individual senior officials' ac counts) have created 2956 Facebook accounts, 1016 Twitter accounts, 695 YouTube channels, and 498 Flickr accounts in the U.S. federal gov ernment [source omitted by author].

For government, social media applications provide the opportunity to integrate information and opinions from citizens into the policy mak ing process in innovative ways, to increase transparency by sharing information on social media channels, and collaborate with the public to prepare decisions or create solutions for government problems. Gov ernment use of social media is publicly observable on the web, what is less know is how internal adoption decisions are made in the highly regulated and guarded information paradigm of government organiza tions in comparison to other types of technology adoption decisions.

\section{Adoption of innovative technology practices in the public sector}

Government technology innovations, their diffusion, related adop tion decisions and implementation approaches have received much attention in the literature. Many studies have focused on the stages 
of adoption, the time it takes government organizations to jump on the bandwagon and start to use a new technology, or the adopter characteristics that shape their decisions. With every wave of new technologies in the public sector, research focuses on the characteris tics of the technology, how it fits into the existing standard operating procedures or how it potentially shapes adopter behavior (Fountain, 2001; Orlikowski, 2000).

In many aspects social media applications can be seen as technologi cal innovations in the public sector. However, the innovation does not necessarily include the soft and hardware aspects of the technology. In stead, the innovative aspects include changes in the way citizens prefer to access their news and government information in their social media newsfeeds that does not align with the current information paradigm in the public sector (Kohut et al., 2008). In other sectors, especially in news and journalism the introduction of social media has lead to major changes, such as the introduction of pay walls or what is now called the 140 character news cycle, referring to the micro blogging service Twitter and its increased importance for journalists as a news source (Pew Research Center's Project for Excellence in Journalism, 2012).

With the introduction of social media applications in government, public managers are therefore facing a high degree of uncertainty. The platforms are hosted and designed by third parties; government has lit tle or no impact on changes of technological features and emergent citizen behavior changes rapidly. The public nature of social media in teractions poses the risk of unintended consequences in form of in creased attention to government operations that most agencies try to avoid. Government communication needs to be reliable, trustworthy, consistent and without major spikes and peaks. Agencies are not trying to compete for attention or for fans and followers with each other. The communication paradigm follows a highly regulated vetting process that does not allow for fast and furious exchanges on social media sites. Changes in the existing paradigm mean a change in behavior and standard operating procedures.

Following Rogers' definition of technology innovation social media applications present a form of technological and behavioral innova tion for government and are therefore perceived as challenging or even disruptive (Christensen \& Overdorf, 2000; Rogers, 1995, 2005). In comparison to other types of ICT or e Government adoption deci sions, such as the use of an agency wide email system or e services, social media applications were not rolled out based on top manage ment decisions and for the use of each department as a whole (see for example Bretschneider, 2003; Heintze \& Bretschneider, 2000; Picazo Vela, Guitierrez Martinez, \& Luna Reyes, 2012). Instead, social media use started mostly through informal experimentation and is slowly gaining traction.

Rogers shows how communication among peers can help spread the positive aspects of a technological innovation through the net work of peers (Rogers, 1995, 2003). According to Rogers innovations "are communicated through certain channels over time among the members of a social system" (1995, p. 5). Hearing best practices from peers can help potential adopters understand the risks and im pact of a new technology and support their decision making process. In this problem space it is therefore important to understand what factors drive the decision to adopt government's use of social media and how the adoption decision results in social media tactics.

Most previous research on the use of social media has focused on publicly observable interactions of government institutions and their use of social media channels (Kavenaugh et al., 2011; Mahler \& Regan, 2011; Picazo Vela et al., 2012). What is less known however is how and why those responsible for the use of social media in government decide to adopt social media practices despite the apparent risks and uncertainties. This question is especially puzzling given that the stan dard communication policies are highly regulated and follow specific norms and regulations (Bertot, Jaeger, \& Hansen, 2011).

The central research question is therefore: How do social media directors canvass their environment to learn about best practices in a context in which rules and regulations evolve in parallel with the use of social media. Specifically, what are the formal and informal in formation sharing mechanisms used by social media directors to ob serve and share best practices? And finally, which distinct online tactics emerge as a result?

\section{Research design}

This paper focuses not only on observable online practices, but seeks to open the 'black box' of government decision making that leads to the adoption of innovative social media tactics in the public sector. While online interactions are publicly observable on social media platforms, such as Twitter or Facebook and the number and types of social media tools are listed prominently on agency's website, the internal conversa tions leading to the use of social media are not publicly observable and rarely communicated to the public.

\subsection{Case selection and context}

In order to understand the early decisions, perceptions about best practices, and information needed to adopt social media applications, insights from the full census of social media directors of all fifteen de partments in the executive branch of the federal U.S. government are included in this study. The departments of the executive branch in clude (USA.gov, 2012):

- Department of Agriculture (USDA)

- Department of Commerce (DOC)

- Department of Defense (DOD)

- Department of Education (ED)

- Department of Energy (DOE)

- Department of Health and Human Services (HHS)

- Department of Homeland Security (DHS)

- Department of Housing and Urban Development (HUD)

- Department of Justice (DOJ)

- Department of Labor (DOL)

- Department of State (DOS)

- Department of the Interior (DOI)

- Department of the Treasury

- Department of Transportation (DOT)

- Department of Veterans Affairs (VA).

There is one primary reason for the selection of this sample: The Transparency and Open Government memo was addressed to the heads of executive departments and follow up directions and regula tions came out in direct reference to the initial memo. This form of theo retical sampling draws clear boundaries around the subjects included in the study and directed the data collection efforts towards a full census of individuals responsible for the implementation of social media in the U.S. federal government (Glaser \& Strauss, 1967; Janelle, 2009). A snowball sampling approach was used to identify and include additional agencies that were perceived as especially innovative by the original sample (Biernacki \& Waldorf, 1981). Five agencies were frequently mentioned by the interviewees and as a result added to the final sample. The overall sample reflects the breadth of all adopters, but also constitutes a full cen sus of all departments in the executive branch of the U.S. federal govern ment. In order to create a quasi counterfactual to the adopter category, the interview partners were asked to provide answers about the barriers other agencies are still facing to use social media.

The interview partners, social media directors in the federal govern ment, can be considered as elites in relatively high level management positions with public exposure (Richards, 1996). The chosen sample in cluded all those individuals in a department with the main responsibil ity for social media interactions and resources. Initially, these social media directors were identified by their job title. Others were added based on their membership in the Federal Web Managers Council and identified by other interview partners. In comparison to other positions, 
such as Chief Information Officers (CIO) or Chief Technology Officers (CTO), social media directors are not responsible for other types of pub lic information systems, such as the investment and implementation decisions related to e Government solutions.

Access to interview partners was either initiated via the micro blogging service Twitter, a direct email request, or in form of a referral by previous interview partners. The majority of the social media direc tors included in this study are institutionally associated with an internal Public Affairs team, highlighting the focus of their activities as part of the department's public communication mission. In only one department this person was located in the IT department and took social media re sponsibilities on in addition to his existing website responsibilities. As so cial media use spread, a new media director or social media director position was officially created with resources to hire staff writers, editors, producers or community managers to administer social media accounts on different platforms.

\subsection{Data collection and analysis}

In preparation for each interview, the department's website and its social media accounts were coded by the type of interactive social media accounts, the number of followers/fans/views, the type of con tent posted online, and the form of online interactions observable on publicly available social media accounts. The semi structured inter views contained questions based on the existing literature on organiza tional decisions for the adoption of innovative technologies. Additional themes that emerged during each interview were captured in interview notes, added to the remaining interviews, and revisited with previous interview partners. The main coding categories evolved from the inter views are included in the following coding themes:

1 Initial reasons for the adoption of social media applications

2 Reasons for the use of selected social media tools

3 Target audience(s)

4 Goals of the social media strategy

5 Managerial day to day processes

6 Specificities of social media policies for daily routines

7 Information search and sharing processes that informed the deci sions to adopt a social media approach ${ }^{1}$

a Information sources

b Internal government sources

c External sources (outside of government)

d Informal conversations

e Formal guidance within the organization

f Passive observations

8 Perceived routines and tactics

9 Top management buy in

10 Perceived barriers for the adoption of social media

11 Perceived outcomes

12 (Current) formal measurement techniques and metrics.

Each interview lasted about $60 \mathrm{~min}$, was recorded with the explicit permission of the interviewee, transcribed verbatim and hand coded paragraph by paragraph. In an iterative process the main themes were derived in a grounded theory like approach (Miles \& Huberman, 1994; NVivo 8, 2008).

The data analysis of the qualitative interviews started immediately after each interview was conducted: initial themes and additional inno vative concepts that were not mentioned in previous interviews were recorded in memos and used for future inquiry. This review resulted in both recurring patterns of social media adoption as well as in new codes. After the initial high level coding procedure, the full interviews were coded line by line to extract patterns in the data following Miles and Huberman's (1994). As an example, all coded interview items

\footnotetext{
${ }^{1}$ Codes 7 and 8 are included in the data analysis of this paper.
}

that described decision making processes for the adoption of social media were clustered, as well as those coded paragraphs that highlight influence factor and social media tactics constitute a cluster.

Moreover, the interview questions about informal and formal guid ance and best practices were coded and resulted in a list of departments that each social media director considers as especially innovative in their use of social media. Each list extracted from the responses was then combined in a sociomatrix that displays the passive attention net work among social media directors (Borgatti, 2002). The passive atten tion network is the list of departments created by each social media director that indicates who they perceive as innovative, pay attention to their online interactions and potentially emulate as best practice. The resulting network matrix is used to understand the informal atten tion network among federal departments and agencies and as an addi tional data point (Wasserman \& Galaskiewicz, 1994; Wasserman \& Faust, 1994).

\section{Findings}

Adoption of social media usage in the U.S. federal government is influenced by two main factors: (1) the passive attention network among social media practitioners, and (2) to a much lesser extent (initially lacking) formal guidance from the top management. As a re sult, government departments observable social media tactics or pathways of their daily use vary across a wide spectrum and intensity of interaction: a) representation, b) engagement, or c) networking. In the following these findings are presented and interpreted.

Social media applications can be labeled as technology innova tions in the public sector. The traditional "press release" style of pub lic communication in government is a highly formalized interaction process set up to mostly inform the public, but rarely for interactive online conversations with the public. The question is therefore to what extent departments and agencies observe each other's online behavior and make the decision to adopt social media practices that evolve outside the existing and accepted communication routines. Social media directors all sit in the same boat and need to fulfill the mandate of the Transparency and Open Government memo to in crease participation, collaboration and transparency. But even before the memo was received the success of the presidential campaign served as a clear indication for the use of social media tools, as one so cial media director points out: "These tools helped the President to get elected that was a big deal." In a space with minimal formal guid ance and institutional knowledge about the use of social media, initial decisions for the use were influenced by the following factors.

\subsection{Influences on adoption decisions}

The interviewed social media directors receive information about innovative use of social media applications through different channels. In some cases they actively search for information and existing best practices in government, in other cases they passively observe and copy other agencies' behavior. The decision to adopt social media prac tices is influenced by four input mechanisms: 1) observations of citizens use of social media; 2 ) passive observations of highly innovative depart ments and agencies; 3 ) active interaction with peers; and 4) formal guidelines developed by lead agencies.

\subsubsection{Market driven information}

The introduction of new technologies in government is traditionally top down driven following organizational needs, technological innova tions, as was the case with PCs, email or Internet use (see for exam ple Ostrowski, 1989). Social media has changed the top down driven adoption procedure: a majority of the departments take a market driven approach. Citizens increasingly use social media to access news and information (PEW Internet \& American Life Project, 2012; Smith, 2011). As a result, government organizations observe these changing 
communication needs of their online audiences. As one social media di rector reports: "The reason we are doing this is that there is a part of our stakeholder group out there that uses Twitter exclusively, or uses Facebook as their main website to get information, to disburse information, to com municate with people. What we want to do is take a buckshot approach, as long as it does not take up a ton of resources. As long as we can manage that, there is no reason not to go out there and be able to communicate with the people in the form in which they are comfortable." The use of social media is therefore targeted toward those parts of a department's online audience who solely use social media applications to receive informa tion and news through their online news feed instead of visiting a gov ernment organization's official website.

Similarly, social media directors argue that parts of their audience have shifted their online behavior and are no longer accessible through traditional media outlets. Social media is seen as a supple ment to existing press mission, as the following quote highlights: "None of our new media communications or tactics takes the place of traditional media. They simply repackage and make things more accept able or appropriate for various audiences." And she goes on to explain that social media helps her department to "create a better sense of un derstanding with stakeholders when we speak in a way that is familiar and comfortable with people, instead of speaking in jargon and acro nyms." These example show that social media is seen as a form of in formal interactions with the public that are otherwise not supported by the traditional communication channels.

\subsubsection{Passive attention network}

Public bi directional online interactions are an innovative form of communication for government agencies. They constitute a departure from the existing communication paradigm and standard operating procedures. Especially early adopters are facing high degrees of uncer tainty about the fast pace of changing citizen expectations and frequent updates of technological features. Rules and policies focus on the use email and Internet, but are retroactively evolving to also cover social media applications. Each interview partner was therefore asked which social media practices of other government organizations they consider as good practices and who they perceive as models for social media use.

Without exception, social media directors report that they are paying attention to online practices of their peers in other departments in the ex ecutive branch of the U.S. federal government. They are browsing websites and sign up to follow each other's social media accounts. Based on their individual observations they evaluate which practices might be of value for their own department. None of the social media directors was able to point out a single agency that is doing everything right, but in stead mention that they are paying attention to several agencies each of which is showing one best practice in one specific communication area.

As one social media director states:"Yes, we take the best practices where we can find them. We are not shy at all about borrowing ideas, especially from other services or other federal agencies, be cause within the federal government it is all fair game. I might have to worry about plagiarism or intellectual property if I borrow some thing outside the federal government. It is fair game from anyone else. [...] If we come across a good example of another federal agen cy doing something well, for example the State Department is doing some very interesting things, I will see if I can emulate some of it."

This quote representative for a majority of the responses indi cates that social media directors are observing each other's online be havior and emulate online practices that fit into their own strategy. It also highlights the non competitive culture among government agen cies. Borrowing best practices crates a public good for citizens and is therefore seen as acceptable behavior in the public sector.

The following figure shows a summary of the "passive" attention net work among federal agencies and departments. The passive nature de scribes how social media directors observe behavior and innovations of others, copy what they perceive as best practices, without actively reaching out to their peers in other departments.

Each interview partner received a pre populated list with the names of all departments in the executive branch of the U.S. government and was asked to indicate those departments that are especially innovative in their use of social media. In addition, they were asked to add organiza tions outside their own branch and sector to the list. The responses are combined in a $\mathrm{n} \times \mathrm{n}$ matrix that includes each department's nomination in each cell.

Blue icons in the network diagram highlight the interviewed depart ments and agencies and red icons highlight agencies and departments that did not respond to the interview request or were added by the in terview partners. Squares indicate agencies, circles departments and triangles highlight the three organizations that are now providing for mal guidance for the use of social media in government, including the White House's New Media Office, GSA's Center for Digital Government, and the Federal Web Managers' Forum. Arrows or links between the nodes indicate that at least one of the interview partners has indicated that they perceive another node as an innovator. The central node the government organization with the most nominations is the White House (six nominations), followed by the Environmental Protection Agency (EPA) and the Department of State (DOS) with four nomina tions each, the Center for Disease Control (CDC) and the Department of Defense (DOD) with three nominations each (Fig. 1):

Other guidance for social media usage comes through a similar channel: passive observations of online best practices outside of gov ernment. Especially online retailers and large e Business companies serve as sources of innovation and replication for government pur poses. Examples include the rating and user interaction services pro vided by Amazon, Zappos, Google, and EBay. Others frequently take in technology guidance and best practices from social media and tech nology blogs such as Mashable.com, or TechCrunch.com.

\subsubsection{Informal knowledge sharing among social media directors}

The overall system of departments and agencies in the executive branch of the federal government is by nature organized in a highly cen tralized fashion: all national headquarters of the departments and agen cies are located in one geographic area and are not scattered around the country. This provides the opportunity for social media directors to build a community of peers with face to face meetings, in addition to weekly phone conferences and webinars organized by the Federal Web Managers' Forum.

While none of these interaction opportunities can be labeled as formal guidance, they do provide opportunities for the social media directors to hear about best practices, ask questions and build a net work of peers to tap into. It also serves as a leveling function especial ly during the early experimentation phase when all social media practitioners operated in a gray area not knowing if their practices are consistent with the existing rules and regulations.

\subsubsection{Formal guidance and institutionalization}

Most formal guidance for the use of social media applications evolves retroactively in response to major mistakes, technological changes by platform providers or observed changes of local behavior specific to a certain social media platform.

The majority of social media directors started to use social media as part of the presidential mandate: "We had to use social media to ac complish the goals of the Open Government and Transparency initiative".

The key hurdle and at the same time driver for the adoption of social media practices include the location of the social media director within the overall organizational hierarchy and the resources dedicated to the use of social media applications. In departments in which social media is regarded as a technological problem, social media responsibility stays with the IT department. In departments where it is seen as part of the mission and included in strategic communication efforts, social media responsibility is located in the public affairs office and 


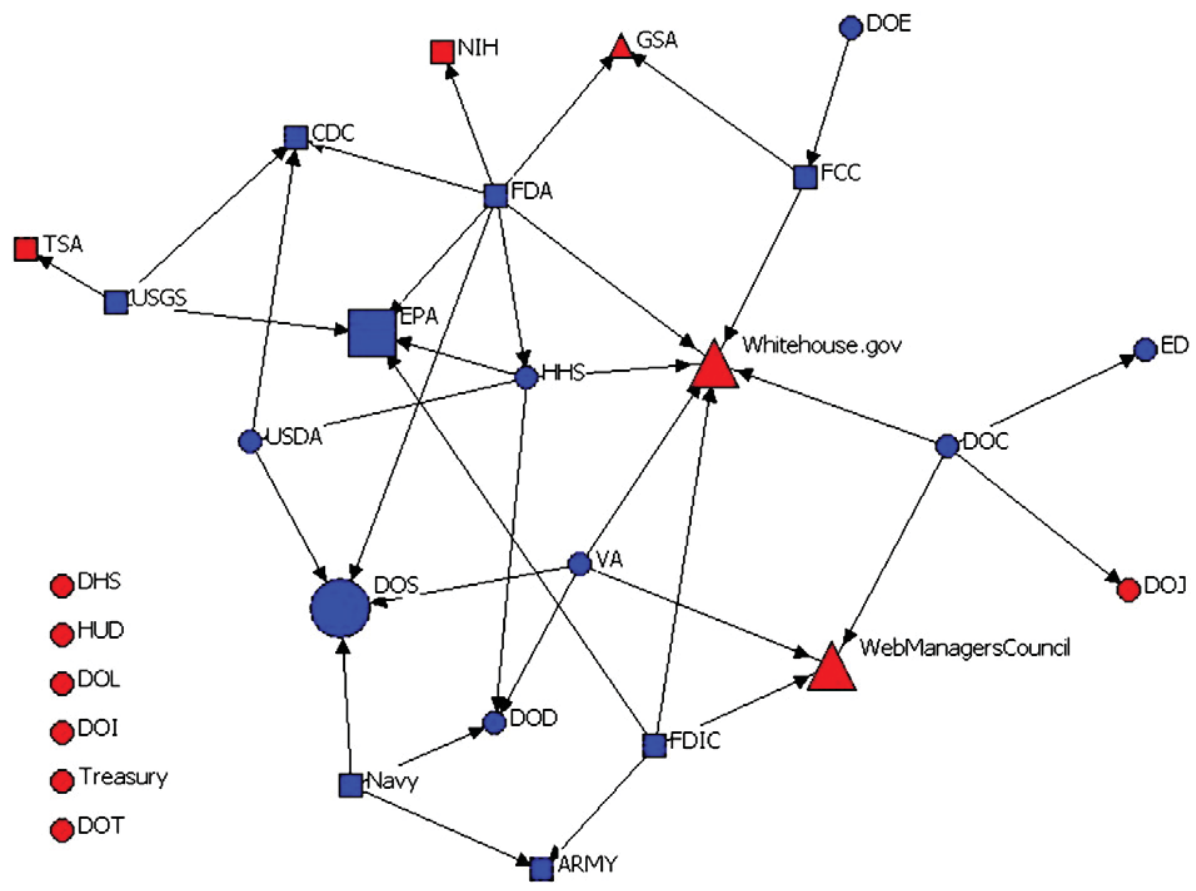

Fig. 1. Social media attention network among federal agencies and departments.

oftentimes knowledge experts in subunits are included in the social media efforts. Over time the importance of social media efforts resulted in business cases that helped early innovators to provide top management with facts and numbers to allocate additional re sources. New organizational structures, such as the new position of a 'Social Media Director' were created as a result, who then actively works on the creation of other institutional norms, such as social media policies to govern the day to day administration of social media accounts, or social media strategies that provide strategic guidance on how to support the mission of the organization.

As opposed to the informal guidance social media directors either search for or can access through their informal networks, there was very little formal guidance provided within each agency. While many are looking at the White House's Office of New Media, the Federal Web Manger's Forum or recently also the General Service Administration's Of fice of Digital Government (GSA), guidance was developed and made available with a significant lag time of over two years in a top down fash ion. As an example, the Social Media Navigator is described by GSA as the guide "to provide government agencies and employees with information about using the many available social media tools." and can be labeled a for mal advice mechanism. ${ }^{2}$ Another guideline is HowTo.gov set up by GSA in 2011 that now gives federal agencies access to concrete guidelines which social media tools to use for what kind of purpose. Nevertheless, the Gov ernment Accountability Office (GAO) reports that the executive depart ments and agencies lack in formal guidance for their use of social media and Web 2.0 applications (Orzag, 2010; Sunstein, 2010).

None of the social media directors mentioned were able to point to formal guidance received through the existing hierarchy or their top management. Instead they were waiting for regulations and guidelines to be set up, such as the Terms of Use agreements with social network ing services in 2010. In some cases this has delayed adoption decision.

\subsection{Social media tactics}

As a result of the broad mandate of the Transparency and Open Government memo, informal observations, and the perceived lack

\footnotetext{
2 See: http://www.gsa.gov/portal/content/277157 (last accessed on May 24, 2011).
}

of formal guidance, departments develop a diverse set of social media tactics.

Social media tactics can be interpreted as pathways or even degree of adoption that are more distinct than the simply adding additional social media channels to a department's website. Tactics can be divid ed into three categories: a) representation of the agency, b) engage ment of citizens, and c) networking with the public. For each of the three areas social media directors provided insights that highlight how each tactic reflects their organization's mission and objectives.

\subsubsection{Representation}

The overwhelming reason to participate in social media spaces can be summarized with one main goal: Representation of the agency on all potential interaction channels. Especially the success of Facebook with about a billion user accounts and Twitter with now 500 million users in 2012 has convinced social media directors that they want to be where citizens are. The following quote is representative for the majority of interview partners:

"Why we're on Facebook or Twitter: to be where the people are. So 400 million users now on Facebook for example, so you want to be there. When people search for [suppressed by author] stuff on Facebook, they find us."

While many agencies maintain several different social media accounts they focus on those social media channels that have the largest number of users including Facebook, Twitter, YouTube, blogs and RSS feeds. Many agencies are experimenting with additional less mainstream social networking services, such as alternative video and photo sharing services or Wikis. The reason for choosing several different channels was stated by the following social media directors: "We wanted to be active in various so cial media spaces." Only those agencies that are targeting younger audi ences or their representatives, such as teachers or professors, also maintained a MySpace account.

The representation objective confirms the need for maximum in clusiveness. Government agencies want to reach audiences in those social spaces they frequent on a daily basis. Several interview part ners recognize the need to reach audiences that do not routinely 
interact with federal agencies and are therefore excluded from decision making and policy making processes. They see the use of additional channels on social media sites as a way to institutionalize their interactions and bring citizens' knowledge into government. The following quote is therefore representative for many agencies: "Get the message out to the audiences that might not normally hear it and have a lower engagement with government."

Agencies that are following a representation tactic as their main social media strategy describe themselves as "by nature very conserva tive organizations" and are repurposing existing online content. They are using social media channels to notify their audiences about policy statements or major press releases.

The resulting social media tactic can be described as a "push strate gy", where minimal additional resources are invested into tailoring the content specifically for social media channels or active bidirectional in teractions. Social media directors in these types of organizations have low confidence in the usefulness of social networking applications. Some actively shut off the commenting function for their Facebook accounts and do not track how their Twitter updates are reused or retweeted through their followers' own networks. Social media chan nels are used because the agencies understand expectations and online destinations where their audiences are interacting and have started to repurpose existing press release style information through social media channels. This centralized approach allows for little innovative interactions or engagement, instead it makes existing content more ac ceptable or appropriate for various audiences.

\subsubsection{Engagement}

The second most frequently mentioned objective to maintain so cial media accounts is engagement. Social media tools are still very new to most agencies and therefore best practices in the public sec tor are rare. Most interview partners perceive their actions as an ex periment in an unknown problem space. Departments recognize that their traditional websites are not the places where citizens search for information: "We hold no illusion that the U.S. government site is going to be the first place that any American citizen will go to get their infor mation." And another social media director points out: "I think it is a fundamental shift: Instead of asking people to come to government, it is government going to the people. People are, for a lack of a better term, hanging out on Facebook, people are hanging out on Twitter. And we want to be sure that our messages can get to people where they want it, when they want it and in the form that they want it. I think it is both a fundamental shift in our approach to that, and also a reaction to just the nature of the technology changing the way people get information."

Departments following an engagement tactic have recognized the need of their audience to interact with government in a natural con versation style, instead of pushing government reports or memos out without providing opportunities for interactions:

"Our social media strategy is to put a face on what has often been a faceless, kind of anonymous or overbearing bureaucracy. Nobody sticks with a press release for more than 23 paragraphs the most."

Even though they are constantly exploring best practices outside of government (such as Starbucks' My Starbucks Idea or BestBuy's Twitter customer service Twelpforce), there are very little role models within government to mirror an interactive engagement approach.

Over time departments are moving from a purely representative and broadcasting tactics to more interactive tactics: "We wanted to engage. But, when we started a year ago, a lot of things were just push. Recognizing that we should be engaging, more so to a pull and listen type of strategy." Several interview partners report that they decided to create a business case with one specific tool first, experiment to gain experiences and insights from their use. Only when they felt they collected enough in sights and were able to make their case, they presented their findings to their top management and ask for additional support. One social media director points out:

"Initially some thought it was just a fad and would detract from the press mission. But I was able to argue for social media as a supplement to supplement our communication as an "and also" approach as opposed to an "and/or" approach."

Recognizing the shortcomings of push strategies, agencies have switched to active "pull strategy". While these practices can still be observed, some agencies have recognized the additional value of so cial media services in allowing bidirectional interactions. Citizens are invited to co produce content that is then replicated on the agen cies' websites, as the following example shows:

"One side of the communication strategy that we did was a little mini campaign called 'Share Your Stories' [...] from there we put together our blog posts [...] pushing them out onto different subnets."

The engagement strategy goes beyond mere broadcasting of infor mation to the public. Instead, agencies are actively trying to encourage their audiences to co create and share content in different formats with them. The engagement strategy in many ways uses social media applications for their initially intended purposes to connect users with each other. Otherwise,

"You are cutting off your visitors' voice if you are not engaging them and not soliciting feedback, and then there is really no point. It's not an effec tive use of the medium. [...] So yes, we allow people to comment openly [on Facebook] and we also go through those. Sometimes we solicit feedback from them by asking questions... and we will follow up on those."

\subsubsection{Networking and "mingling"}

The last tactic evolved based on the recognition that government organizations do not always have to play an active engagement role when they are using social media applications. Instead, it is often times important to keep a measured voice, stay on message and use social media applications to listen to citizens. This tactic allows gov ernment to absorb comments, gain valuable insights about the senti ments around mission relevant issues or emergent topics their perceived online audiences talk about across social media channels. As one of the social media directors said in this representative quote:

"Given the opportunity, people are really excited and willing to pro vide really fantastic insight in things that help us get closer to the tax payer and to the people that we serve by listening."

The agency adopting a networking strategy provides the social media tools to facilitate conversations and "mingling" opportunities among its stakeholders. They are engaging their agency's knowledge experts to co write strategic plans or policies with a knowledgeable audience.

This highly interactive and bidirectional responsiveness of the agency produces reciprocated feedback cycles. While several social media directors mentioned this objective, very few interview part ners were able to point to examples, instead they listed reciprocated feedback and interaction as a desirable goal for their social media use.

Allowing audiences to reuse a government organization's social media content can be interpreted as another indicator of a network ing strategy. This includes for example cases where a department al lows citizens to leave comments on their Facebook fan page or 
YouTube videos, and to share official government content. In the fol lowing, one social media director explains their use of YouTube:

"We started talking about YouTube because we have quite a video li brary, and we wanted to find a way to socialize and make it more easy for people to find, make it more easy for people to share it."

A networking tactic of a social media strategy therefore does not necessarily only include active interactions with the public, instead it can be seen as an enhanced interaction of the public with the con tent an agency is producing and a snowballing of the content through the audience's own networks. This gives the public on the one hand a larger responsibility and control over the content. On the other the agency itself has to come to a more generous understanding of their own role and responsibility as a partner in the overall network. It ac tively has to leave the conversation to the people, instead of guiding, constraining or controlling the content.

\section{Discussion}

How and why are government organizations deciding to adopt so cial media practices that are seemingly conflicting with the standard operating procedures of the formal press mission? In this paper, I have examined the different localities that social media directors are using to access information about best practices, experiences and guid ance for their own use of social media applications. The factors that are driving the decisions to adopt innovative web practices include passive observations and comparisons of government and as well as corporate best practice examples (i.e., from Amazon or Mashable.com), the infor mal attention network among departments, and to a certain extent also some formal guidance.

The lack of formal guidance has in turn led government agencies to their own devices and social media professionals are mostly exper imenting with social media tactics. They have to defend the use and use fulness to their top management and critics who perceive the adoption of social media applications as a fad that will pass (Abrahamson, 1991). The factors leading to the adoption decisions have shown that especially tech nology that was not rolled out based on a top down management deci sion, such as email or web services, is modeled based on informal and passive observations of practices both in other government departments, but also in the corporate sector. The information on how to adopt spills over from agency to agency and mostly travels through informal conver sations in the network of peers (Abrahamson \& Rosenkopf, 1997; Rogers, 1976; Rogers \& Shoemaker, 1971).

Depending on each agency's existing communication and interac tion style, social media professionals are taking on three distinguishable social media tactics: a push strategy to represent formal government in formation on social media as additional channels; a pull strategy to en gage and include information from the public; and a networking strategy that includes both push and pull activities, but also leaves room for engagement beyond active involvement of government, as shown in the overview in the following Table 1.

While many different regulations for interaction between government and the public exists, the Open Government memo did initiate the use of social media. The extent of the interpretation of the memo text as well as the direction in which departments are actively using social media vary widely. Even though all social media directors acknowledge that the need and incentive to use social media, many also highlight, that innova tion is driven by their audiences' behavior. This market driven innovative citizen behavior therefore drives adoption in government a reactionary decision making process that put many agencies into a defensive position and increases the need to navigate this unknown problem space. Government observes behavior of its stakeholders online and reacts to the changes in preferences by using social media as a new pre ferred information channel to receive news and information.

What did come as a surprise in this study is that traditional market mechanisms do not seem to play a role in these early adoption decisions (Lazer, Mergel, Ziniel, Esterling, \& Neblo, 2011). As opposed to other technological innovations, vendors or consultants at this point and in the perceptions of social media directors do not play a role in early adoption decisions. This might have to do with the free and open source nature of the social media applications, the speed of the dif fusion and the fact that practices of others' successful use can be openly observable on the web and are easy to emulate.

Moreover, non existent or just barely emerging formal guidelines don't seem to stall experimentation with social media. Instead all inter view partners did report an adoption strategy of social media applica tions, even though they receive very little top down guidance. Many departments therefore had to find a way to navigate this highly innova tive and volatile environment to understand how they can translate existing practices into a new online environment. The passive attention network with highly observable practices plays a major role: central agencies and departments receive a lot of attention, even if they are catering toward different audiences the applicability of practices therefore transcends audiences and agency specific content.

\section{Opportunities for future research}

This study has focused on a specific set of early adopters and the factors that influenced their individual decision making to adopt so cial media applications in the public sector. The cohort of social media directors in the executive branch of the U.S. federal govern ment has specific characteristics and their decision, direction and speed of adoption were highly influenced by a presidential directive. Future research is needed to understand whether the diffusion across all branches of the federal government, but especially the state and local government levels is driven by similar factors.

What is necessary going forward is an in depth understanding of the nature of the impact social media interactions provide for govern ment. Do they help government organizations to increase the quality and effectiveness of their processes by including diverse opinions

Table 1

Summary of social media adoption tactics.

\begin{tabular}{|c|c|c|c|c|c|c|c|}
\hline Location & Strategy & $\begin{array}{l}\text { Business } \\
\text { value }\end{array}$ & Tactic & Policy & \# of accounts & Resources & Information vetting \\
\hline $\begin{array}{l}\text { IT } \\
\text { department }\end{array}$ & Representation & $\begin{array}{l}\text { Informational } \\
\text { broadcasting }\end{array}$ & Push & $\begin{array}{l}\text { No interactions allowed, } \\
\text { commenting disabled }\end{array}$ & $\begin{array}{l}\text { One account for } \\
\text { the whole agency }\end{array}$ & None & $\begin{array}{l}\text { Typical information clearing } \\
\text { process as for any public } \\
\text { statement }\end{array}$ \\
\hline $\begin{array}{l}\text { Public affairs } \\
\text { office }\end{array}$ & Engagement & Educational & Pull & $\begin{array}{l}\text { Dedicated social media } \\
\text { policy (i.e., commenting } \\
\text { policy) }\end{array}$ & $\begin{array}{l}\text { Official public } \\
\text { affairs } \\
\text { account plus } \\
\text { agency accounts }\end{array}$ & $\begin{array}{l}\text { Dedicated social media } \\
\text { department, incl. staff and } \\
\text { budget }\end{array}$ & $\begin{array}{l}\text { Information vetting for } \\
\text { repurposed statements; } \\
\text { ad hoc interactions }\end{array}$ \\
\hline $\begin{array}{l}\text { Knowledge } \\
\text { experts }\end{array}$ & Mingling & $\begin{array}{l}\text { Transactional \& } \\
\text { empowering }\end{array}$ & Networking & $\begin{array}{l}\text { Open exchanges with } \\
\text { social media guidelines }\end{array}$ & Unrestricted & $\begin{array}{l}\text { Dedicated social media } \\
\text { department, incl. staff and } \\
\text { budget } \\
\text { Plus expert accounts }\end{array}$ & $\begin{array}{l}\text { Information vetting for } \\
\text { repurposed statements; } \\
\text { ad hoc interactions; } \\
\text { "responsible" exchanges }\end{array}$ \\
\hline
\end{tabular}


from the public? Are they improving the standard operating proce dures because of a more efficient and effective use of technology?

Bertot et al. point out that it is still unclear if the technological poten tial is fully used or has even proven its value yet (NASCIO, 2011). Gov ernment at this point has little experience extracting innovative knowledge out of the exchanges on social media sites. It is unclear to what extent the information that flows into government is governed, processed, used and how government acts on information that is creat ed with and among their audience members in conversations on social media platforms. Social media applications provide an innovative mechanism to incubate innovative knowledge outside of government. Social media provides ways to break up knowledge silos in the public sector (within government, across departments and jurisdictions, but also with citizens and among civil society) (Bretschneider \& Mergel, 2010; McClure, 2010; Mergel, 2011). Additional research is necessary to understand the implications of social media strategies and adoption pathways. The question is therefore: Are social media tools indeed in creasing transparency, accountability, participation and collaboration in government? And how do social media interactions instill innova tive knowledge and ideas into government? To what extent can govern ment channel the knowledge into actionable knowledge?

Finally, future research can help academics and practitioners alike to understand if social media interactions are designed effectively enough to reach the right audiences of a government agency. Do these interac tions have an impact on both the organization and citizens? And, what are the appropriate metrics government is a) allowed to apply to under stand their impact, and b) that can help government interpret and understand its impact in the use of social media.

\section{References}

Abrahamson, E. (1991). Managerial fads and fashions: The diffusion and rejection of innovations. Academy of Management Review, 16(3), 586-612.

Abrahamson, E., \& Rosenkopf, L. (1997). Social network effects on the extent of innovation diffusion: A computer simulation. Organization Science, 8(3), 289-309.

Bertot, J. C., Jaeger, P. T., \& Hansen, D. (2011). The impact of polices on government social media usage: Issues, challenges, and recommendations. Government Information Quarterly, http://dx.doi.org/10.1016/j.giq.2011.04.004.

Biernacki, P., \& Waldorf, D. (1981). Snowball sampling: Problems and techniques of chain referral sampling. Sociological Methods Research, 10(2), 141-163.

Borgatti, S. P. (2002). NetDraw 2.0 (Version Release 1.0.0.27).

Boyd, D. M., \& Ellison, N. B. (2007). Social network sites: Definition, history, and scholarship. Journal of Computer-Mediated Communication, 13(1) (Retrieved from http://jcmc.indiana.edu/vol13/issue1/boyd.ellison.html)

Bretschneider, S. (2003). Information technology, E-Government, and institutional change. Public Administration Review, 63(6), 738-741.

Bretschneider, S., \& Mergel, I. (2010). Technology and public management information systems: Where have we been and where are we going. In D. C. Menzel, \& H. J. White (Eds.), The state of public administration: Issues, problems and challenges (pp. 187-203). New York: M.E. Sharpe, Inc.

Christensen, C. M., \& Overdorf, M. (2000). Meeting the challenge of disruptive change. Harvard Business Review, 65-76.

Fountain, J. E. (2001). Building the virtual state: Information technology and institutional change. Washington, D. C.: Brookings Institution Press.

Glaser, B. G., \& Strauss, A. L. (1967). The discovery of grounded theory: Strategies for qualitative research. New York: Aldine Publishing.

Heintze, T., \& Bretschneider, S. (2000). Information technology and restructuring in public organizations: Does adoption of information technology affect organizational structures, communications, and decision making? Journal of Public Administration Research and Theory, 10, 801-830.

Janelle, R. (2009). GCPedia a success, says Government of Canada CIO. Retrieved from. http://www.techvibes.com/blog/gcpedia-a-success-says-government-of-canada-cio

Kavenaugh, A., Fox, E. A., Sheetz, S., Yang, S., Li, L. T., Whalen, T., et al. (2011). Social media use in government: From the routine to the critical. Paper presented at the The Proceedings of the 12th Annual Inernational Conference on Digital Government Research, dg.O'11 York, NY, USA: ACM New.

Kohut, A., Keeter, S., Doherty, C., Dimock, M., Parker, K., Remez, M., et al. (2008). Internet overtakes newspapers As news outlet - Biggest Stories of 2008: Economy tops campaign. Retrieved 03/27/2011, from. http://people-press.org/report/479/internet-overtakesnewspapers-as-news-source
Lazer, D., Mergel, I., Ziniel, C., Esterling, K. M., \& Neblo, M. A. (2011). The multiple institutional logics of innovation. International Public Management Journal, 14(3), 311-340.

Mahler, J., \& Regan, P. M. (2011). Federal agency blogs: Agency mission, audience, and blog forms. Journal of Information Technology \& Politics, 8(2), 163-176.

McClure, D. (2010). Congressional testimony: Dave McClure, associate administrator for citizen services and innovative technologies, testifies on federal agency use of Web 2.0 technologies. Retrieved from. http://159.142.75.50/portal/content/158009

Mergel, I. (2010). Government 2.0 revisited: Social media strategies in the public sector. PA Times, American Society for Public Administration, 33(3), 7 \& 10.

Mergel, I. (2011). The use of social media to dissolve knowledge silos in government. In R. O'Leary, S. Kim, \& D. VanSlyke (Eds.), The future of public administration, public management, and public service around the world.

Miles, M. B., \& Huberman, A. M. (1994). Qualitative data analysis: An expanded sourcebook (2nd ed.). Thousand Oaks: Sage Publications.

NASCIO (2011). NASCIO and attorneys general negotiate model Facebook agreement for state government use. Retrieved from. http://www.nascio.org/newsroom/ pressrelease.cfm? $\mathrm{id}=93$

NVivo 8 (2008). NVivo qualitative data analysis software (version 7th). Melbourne: QSR International Pty Ltd.

Obama, B. (2009). Transparency and open government: memorandum for the heads of executive departments and agencies. Whitehouse Blog. Retrieved from. http:// www.whitehouse.gov/the_press_office/TransparencyandOpenGovernment/

Orlikowski, W. J. (2000). Using technology and constituting structures: A practice lens for studying technology in organizations. Organization Science, 11(4), 404-428.

Orzag, P. (2010). Guidance for agency use of third-party websites and applications Memorandum for the heads of executive departments and agencies. (Retrieved from http://www.whitehouse.gov/sites/default/files/omb/assets/memoranda_2010/m1023.pdf)

Ostrowski, J. W. (1989). Implementing microcomputer systems in the public organization. International Journal of Public Administration, 12(4), 533-561.

PEW Internet \& American Life Project (2012). 65\% of online adults use social networking sites. Retrieved from. http://www.pewinternet.org/Reports/2011/ Social-Networking-Sites.aspx

Pew Research Center's Project for Excellence in Journalism (2012). The state of news media 2012: What Facebook and Twitter mean for news. Retrieved from. http://stateofthemedia.org/2012/mobile-devices-and-news-consumption-somegood-signs-for-journalism/what-facebook-and-twitter-mean-for-news/

Picazo-Vela, S., Guitierrez-Martinez, I., \& Luna-Reyes, L. F. (2012). Understanding risks, benefits, and strategic alternatives of social media applications in the public sector. Government Information Quarterly, 29, 504-511.

Richards, D. (1996). Elite interviewing: Approaches and pitfalls. Politics, 10(3), 199-204.

Rogers, E. M. (1976). New product adoption and diffusion. The Journal of Consumer Research, 2(4), 290-301.

Rogers, E. M. (1995). Diffusion of innovations (4th ed.). New York: Free Press.

Rogers, E. M. (2003). Diffusion networks. In R. Cross, A. Parker, \& L. Sasson (Eds.), Networks in the knowledge economy (pp. 130-179). New York: Oxford University Press.

Rogers, E. M. (2005). Adoption of innovation. New York: The Free Press.

Rogers, E., \& Shoemaker, F. F. (1971). Communication of innovation: A cross-cultural approach (2nd edition). New York, NY: Free Press.

Smith, A. (2011). Why Americans use social media. Retrieved from. http://www. pewinternet.org/ /media//Files/Reports/2011/WhyAmericansUseSocialMedia.pdf

Sunstein, C. R. (2010). Information collection under the paperwork reeducation act. Retrieved from. http://www.whitehouse.gov/sites/default/files/omb/ assets/inforeg/PRAPrimer_04072010.pdf

USA.gov (2012). Federal executive branch. Retrieved 09/17/2012, from. http://www. usa.gov/Agencies/Federal/Executive.shtml-Executive_Departments

Wasserman, S., \& Faust, K. (1994). Social network analysis: Methods and applications (structural analysis in the social sciences). Cambridge: Cambridge University Press.

Wasserman, S., \& Galaskiewicz, J. (Eds.). (1994). Advances in Social Network Analysis: Research from the Social and Behavioral Sciences. Newbury Park, CA: Sage Publications.

Watts, D., Dodds, S., \& Newmark, M. (2002). Identity and search in social networks. Science, 296(5571), 1302-1305.

Ines Mergel is an Assistant Professor of Public Administration and International Affairs at the Maxwell School of Citizenship and Public Affairs and The Information Studies School (ischool) at Syracuse University. She was previously a postdoctoral research fellow at Harvard's Kennedy School of Government, Program of Networked Governance and the National Center for Digital Government. Professor Mergel teaches in the Master of Public Administration program courses on Government 2.0, New Media Management in the Public Sector, Networked Governance, and Public Organizations \& Management. Her research interest focuses on informal networks among public managers and their adoption and use of social media technologies in the public sector. In particular, she studies how public managers search, share and reuse knowledge they need to fulfill the mission of their agency.

A native of Germany, Professor Mergel received a B.A. and M.B.A.-equivalent in business economics from the University of Kassel, Germany. She received a Doctor of Business Administration (D.B.A.) in information management from the University of St. Gallen in Switzerland and spent six years as pre- and postdoctoral fellow at Harvard's Kennedy School of Government where she conducted research on public managers' informal social networks and their use of technology to share knowledge. 